DOI 10.17816/transsyst201843s1195-202

\author{
(C) R. Stephan ${ }^{1}$, F. Costa ${ }^{1}$, E. Rodriguez ${ }^{1}$, Z. Deng ${ }^{2}$ \\ ${ }^{1}$ Laboratory of Applied Superconductivity (LASUP/UFRJ) \\ (Rio de Janeiro, Brazil) \\ ${ }^{2}$ State Key Laboratory of Traction Power (SWJTU) \\ (Chengdu, China)
}

\title{
RETROSPECTIVE AND PERSPECTIVES OF THE SUPERCONDUCTING MAGNETIC LEVITATION (SML) TECHNOLOGY APPLIED TO URBAN TRANSPORTATION
}

A review of the Superconducting Magnetic Levitation (SML) technology applied to urban transportation will be presented. The historical time line will be highlighted, pointing out the pioneering efforts at Southwest Jiatong University (SWJTU), China, followed by the Supra Trans project in IFW-Dresden, Germany, and the MagLev-Cobra project in UFRJ, Brazil.

Background: Details of the MagLev-Cobra project, the first, and until today the single one, applying the SML technology that counts with a real scale prototype, operating regularly in open air, will be disclosed. The inauguration of the MagLev-Cobra project was on the $1^{\text {st }}$ October 2014, the last day of the " $22^{\text {nd }}$ International Conference on Magnetically Levitated Systems and Linear Drives (MAGLEV)" held in Rio de Janeiro. Curiously, this day coincides with the $50^{\text {th }}$ anniversary of the successful operation of the Shinkansen in Tokyo. On the $1^{\text {st }}$ October 1964 , the first high-speed wheel and rail train in the world was inaugurated in time for the first Olympic Games that took place in Asia. This historical coincidence is a good omen for the MagLev-Cobra project. In fact, since October 2014, the system operates regularly for demonstration at the UFRJ Campus, every Tuesday. More than 12.000 visitors have already had the opportunity to take a test ride.

Aim: The Proceedings of the MAGLEV conferences, which first edition dates back to 1977 (http://www.maglevboard.net), are the documentary files of the importance of this achievement. Initially, the methods named Electromagnetic Levitation (EML) and Electrodynamic Levitation (EDL) were considered.

Methods: At the end of last century, due to the availability of Rare Earth Permanent Magnets and High Critical Temperature Superconductors (HTS), an innovative levitation method, called Superconducting Magnetic Levitation (SML), started to be considered. This method is based on the flux pinning effect property of HTS in the proximity of magnetic fields given by rare earth permanent magnets. The first experiments with SML, as expected, were small scale prototypes, or laboratory vehicles for one, two or four passengers, proposed mainly by researchers from Germany, China and Brazil. The Proceedings of the $16^{\text {th }}$ MAGLEV, held in year 2000, confirms this fact. After 14 years of research and development, the team of the Laboratory of Applied Superconductivity (LASUP) of UFRJ achieved the construction of the first real scale operational SML vehicle in the world.

Results: This retrospective will be followed by a comparison with the EML technology, that has already four urban commercial systems, will be presented and the application niches delimited. 
Conclusion: The perspectives of the MagLev-Cobra project and the cooperation efforts with China to turn it a commercial experience will finish the paper. As will be explained, before the commercial application of the MagLev-Cobra technology, the system must be certified and the technical, economic and environmental viability for a first deployment concluded.

Keywords: Superconducting Magnetic Levitation, Urban Transportation, Superconductors, Rare Earth Permanent Magnets, Technology Readiness Level, Route for Commercialization.

\section{INTRODUCTION}

All big steps in the evolution of mankind can be related with the use in large scale of a new material to make objects. For instance: wood, bones, flint stones, iron, brass, steel. During the last century, the invention of the controlled semiconductor, in 1947, by Bardeen, Schockley and Brattain changed the world and inaugurated a new era that deserves to be referred in the future as the semiconductor era. Nowadays, a great variety of available new materials turns it difficult, even impossible, to select one to characterize the period, e.g.: graphene, carbon fiber, glass fiber, nanomaterials, superconductors and permanent magnets.

The Superconducting Magnetic Levitation (SML) technology is based on the use of high critical temperature superconductors (HTS) and rare earth permanent magnets, that dates back to 1987 [1,2]. The availability of these materials for commercial applications, as expected, took some years. Therefore, the first prototypes of SML MagLev appeared at the turn of the century, practically 40 years later than the available prototypes of EML and EDL MagLev vehicles.

Disregarding small demonstrations, the first man loaded example of SML has been presented in Chengdu, by Wang and his research group [3] in 2002. This example was not only improved by Wang' fellow students $[4,5]$, but was also followed by prototypes in Dresden, Germany [6] and Rio de Janeiro, Brazil [7, 8]. These initial systems operated inside the laboratory, in controlled environmental conditions and just for demonstration. The first and until today the single prototype that operates outdoors, presenting the conditions of a real transportation system, is the MagLev-Cobra project, that will be described in the following.

\section{THE MAGLEV-COBRA VEHICLE}

The prototype was inaugurated on the $1^{\text {st }}$ October 2014, the last day of the $22^{\text {nd }}$ International Conference on Magnetically Levitated Systems and Linear Drives. The conference participants were able to ride in the vehicle and test the system, which, at that time, still had some restrictions of operation as a recently inaugurated project. 


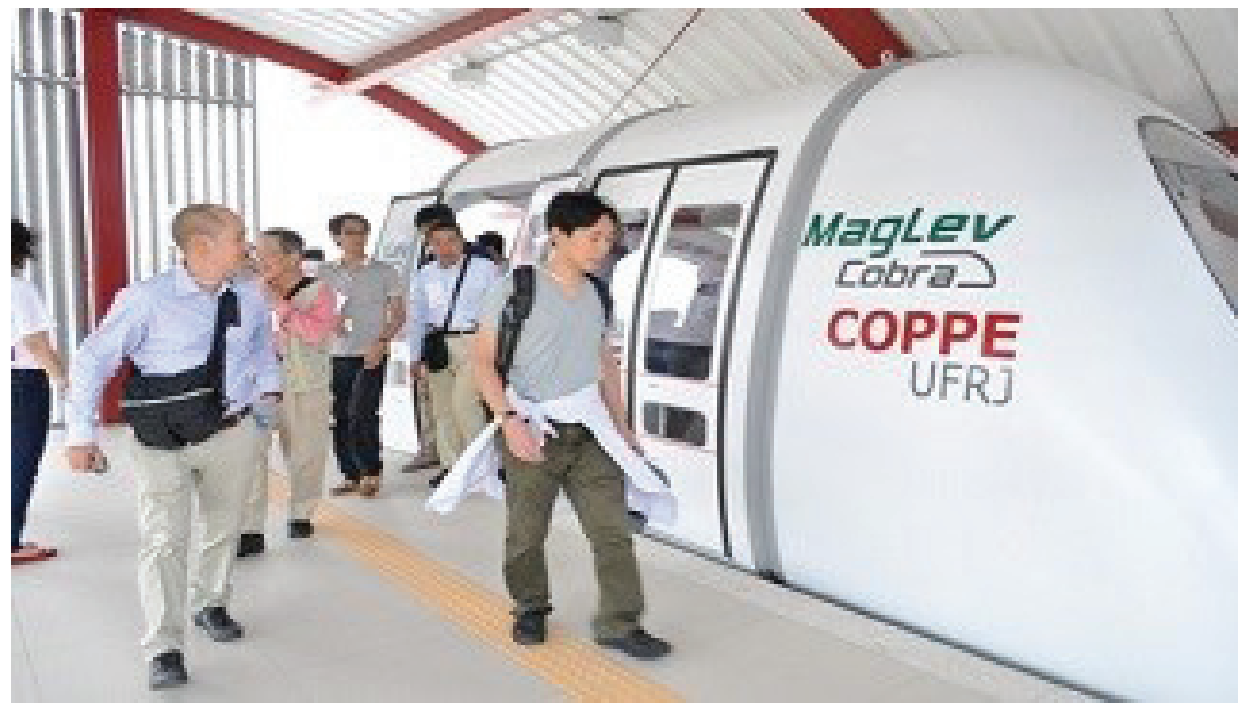

Fig. 1. The last day of MagLev Conference in 2014

After one year of improvements, regular demonstrations, every Tuesday, started to visitors. The line is 200 meters long and the vehicle can carry 20 passengers at a speed of $12 \mathrm{~km} / \mathrm{h}$. Until today, more than twelve thousand persons experienced the ride $[9,10]$.

The graphical abstracted depicted in Fig. 3 summarizes the technology and a figure says more than thousand words.

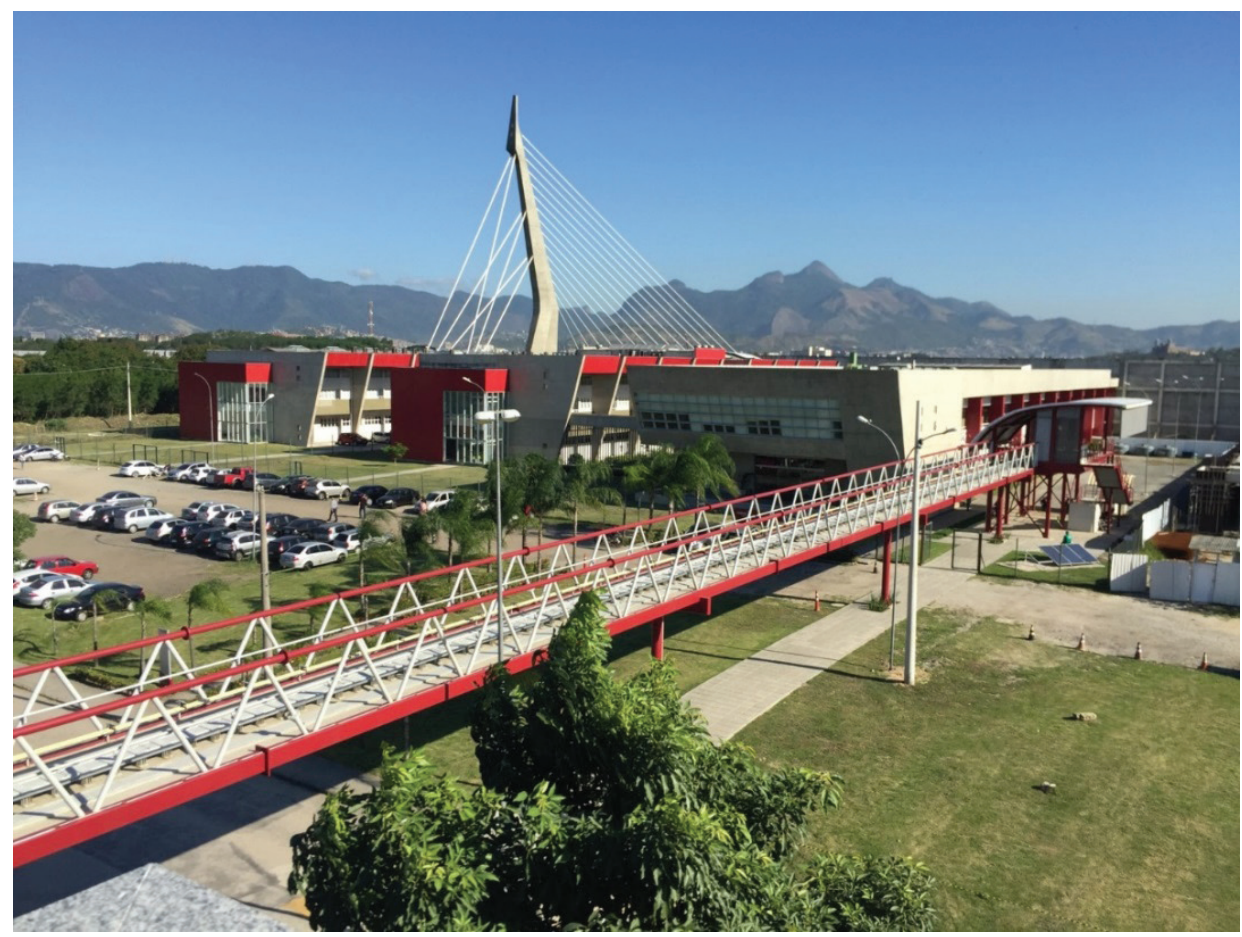

Fig. 2. The 200 meters long elevated line of MagLev-Cobra 


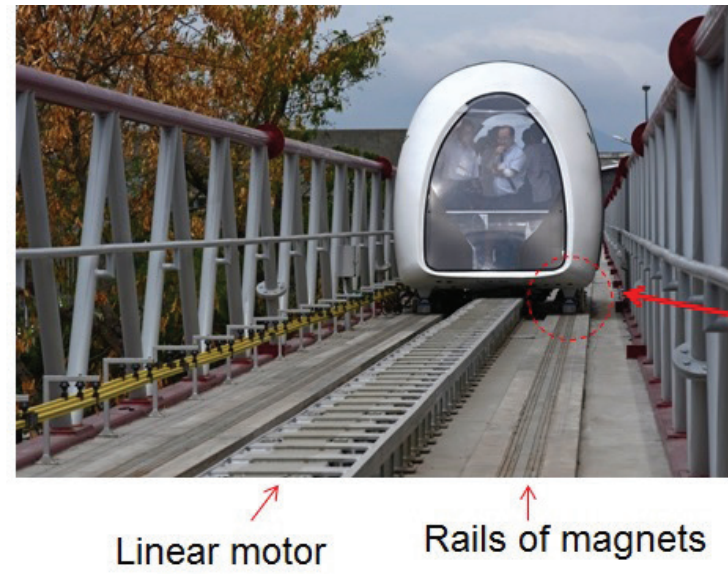

200 meters long line - outside the laboratory Vehicle for 20 passengers

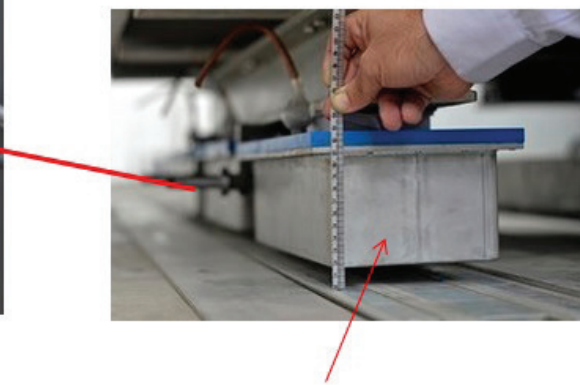

Superconductors refrigerated with

$\mathrm{LN}_{2}$ inside of cryostats

Fig. 3. Graphical abstract of the MagLev-Cobra project

\section{NASA'S TECHNOLOGY READINESS LEVELS}

According to the Technologic Readiness Level $[11,12]$ proposed by NASA and summarized in Table 1, the MagLev-Cobra has reached TRL7.

Table 1. NASA's Technology Readiness Levels

\begin{tabular}{|c|c|c|}
\hline Level & Description & Main characteristic \\
\hline TRL1 & Basic principles observed and reported & \multirow{3}{*}{$\begin{array}{l}\text { Small scale } \\
\text { Proof of concept }\end{array}$} \\
\hline TRL2 & Technology concept and/or application defined & \\
\hline TRL3 & Proof of concept validation & \\
\hline TRL4 & Validation in laboratory environment & \multirow{2}{*}{$\begin{array}{l}\text { Full scale } \\
\text { Laboratory environment }\end{array}$} \\
\hline TRL5 & Validation in a relevant environment & \\
\hline TRL6 & Validation in a relevant final environment & \multirow{2}{*}{$\begin{array}{l}\text { Full scale } \\
\text { External environment }\end{array}$} \\
\hline TRL7 & Validation in an operational environment & \\
\hline TRL8 & "Mission qualified" trough test and demonstration & \multirow{2}{*}{ First product } \\
\hline TRL9 & "Mission proven" trough successful operations & \\
\hline
\end{tabular}

In fact, for the large scale commercialization, which is not usually the main objective of NASA, a $10^{\text {th }}$ level should be added, as proposed in Table 2.

Table 2. A new Technology Readiness Level to encompass the commercialization

\begin{tabular}{|c|l|l|}
\hline Level & \multicolumn{1}{|c|}{ Description } & \multicolumn{1}{c|}{ Main characteristic } \\
\hline TRL10 & Production, sales and marketing chain established & Series production \\
\hline
\end{tabular}


The efforts to reach each level increases considerably at each step. The number of person engaged in the activity and the amount of invested money progress geometrically at a rate greater than two. Therefore, to turn the SML Technology a final product, i.e. to reach TRL10, Brazil and China established recently a cooperation named "China-Latin American United Laboratory for Rail Transportation".

\section{APPLICATION NICHE}

The main cost of the SML technology rests on the Permanent Magnetic (PM) Rail. Since high speed implies necessarily large distance, which would represent a huge cost on PM, the application niches of SML are short distances, low speed $(\sim 70 \mathrm{~km} / \mathrm{h})$ urban transportation. For such applications, the EDL technology, which requires velocity to achieve levitation, does not offer a great appeal. In fact, presently, all commercially operated urban MagLev systems (HSST in Japan since 2005, ECO-Bee in South Korea since 2016, and Changsha and Beijing lines in China, since 2016 and 2017, respectively) uses EML technology.

The authors of this paper support that the SML method offers advantages in comparison with the EML solution for application in urban areas. The following items will support this statement based on two points: the simplicity and robustness of the levitation method; the simple and slimmer civil engineering construction.

\section{COMPARISON EML X SML: LEVITATION SYSTEM}

The SML technology is intrinsically stable, just the PM rail and the cryostats (the "wheels" of this technology) are necessary to achieve levitation, as already shown in Fig. 3. On the other hand, the stability of the EML can be obtained only with a closed loop control system, which requires sensors, signal processing, A/D and D/A converters, EMI (Electromagnetic Interference) reduction, back-up energy supply and heavy and bulk electromagnetic actuators made of iron core and copper windings. Fig. 4 turns this advantage of the SML technology evident.

\section{COMPARISON EML X SML: CIVIL ENGINEERING CONSTRUCTION}

As a direct consequence of the simplicity of the SML method and its lower weight, the civil engineering construction of the SML technology presents advantages in comparison with EML systems, as shown in Fig. 5. As proof of this, the Brazilian prototype for 20 people weighs only 2.3 tons empty. 

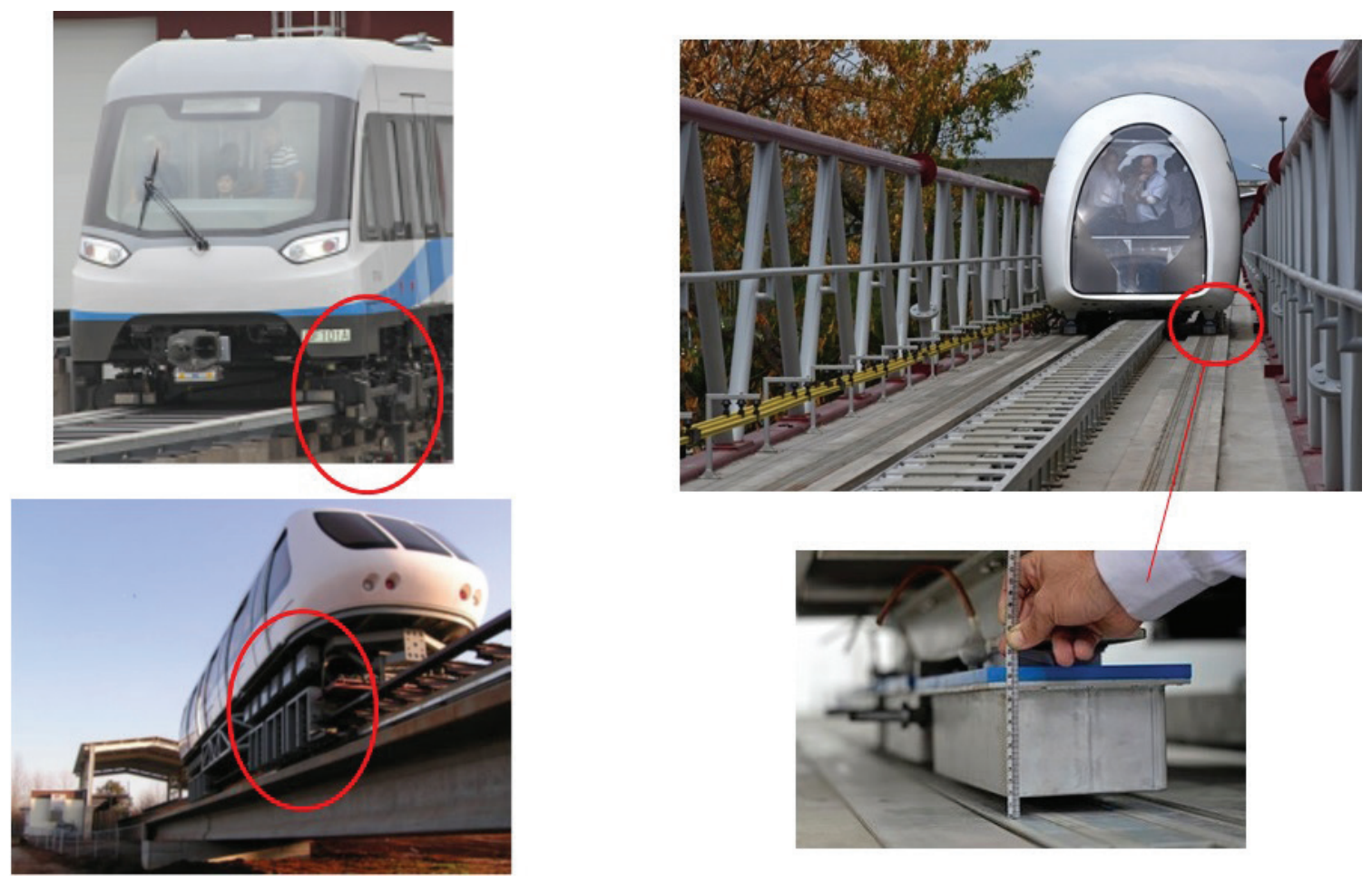

Fig. 4. The EML levitation method (two examples on the left side) in comparison with the SML levitation equipment (on the right)
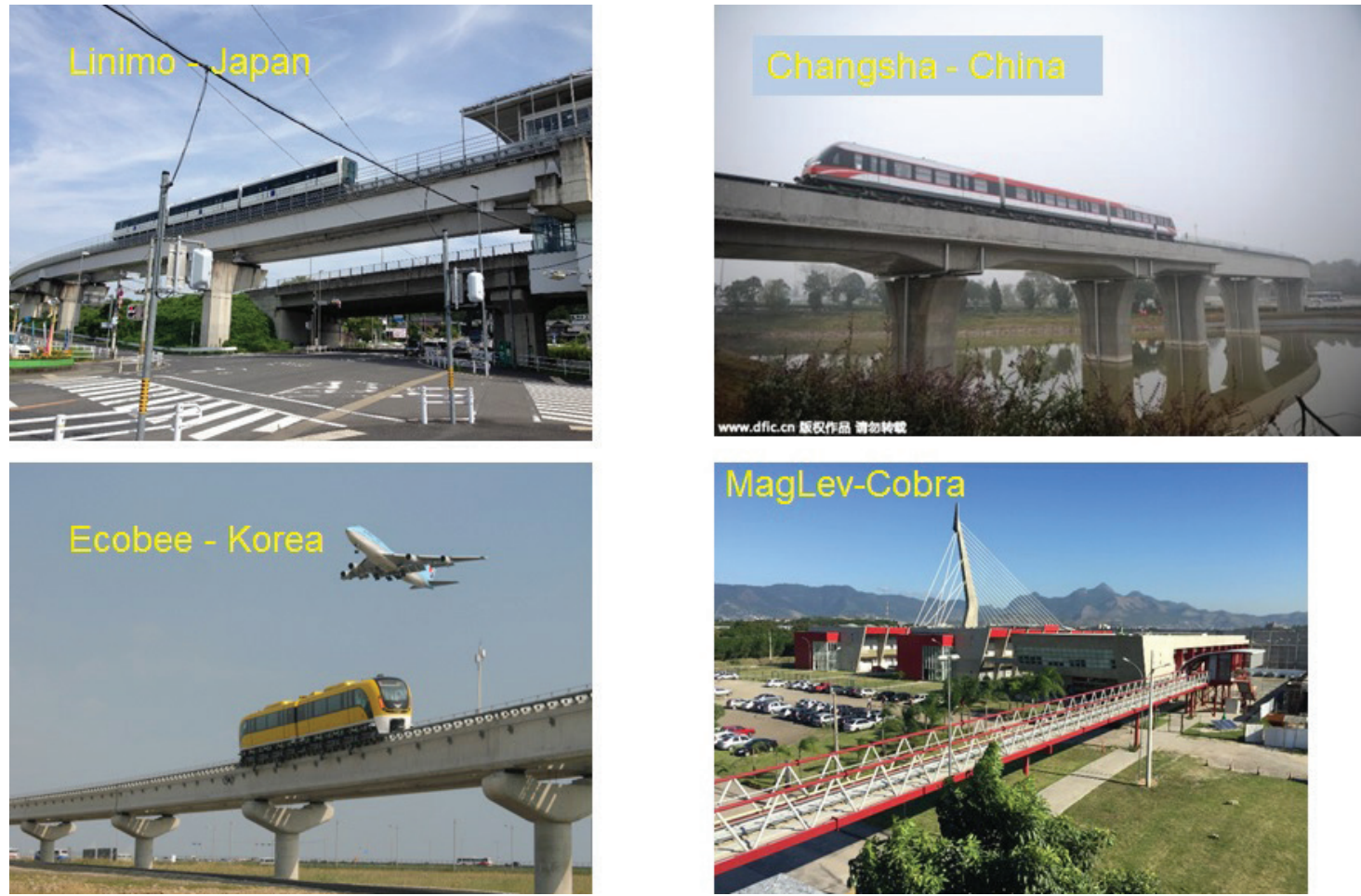

Fig. 5. The EML civil engineering construction (three commercial lines) in comparison with the real scale prototype of the SML technology 


\section{ROUTE FOR COMMERCIALIZATION}

To confirm the arguments presented in the last paragraphs, and climb levels TRL8, TRL9 and TRL10, an experimental line of the SML technology, one to two kilometers long, with curves, declivities and switches have to be constructed. The investment necessary is in the order of magnitude of $10^{7} \mathrm{US} \$$. Similar steps and levels of investment have been followed by other transportation systems. The participation of Public and Private capital, forming a Partnership, the so-called PPP, is under negotiation. Along this process, the production chain will be established and the flourishment of new companies are foreseen.

\section{CONCLUSION}

This paper presented the state of the art of the disruptive MagLev Technology based on flux-pinning property of superconductors in the proximity of permanent magnets, the SML method. The technology is promising. Efforts are in course to construct a test line with all characteristics of a commercial system.

The sentence coined by the colleagues of KIMM (Korean Institute of Machinery and Materials) on the occasion of the 2011 MagLev conference, held in Daejon, lends itself very well to conclude this article: "MagLev trains are not just ordinary trains but wings that will help mankind take another leap forward in the future".

\section{ACKNOWLEDGMENT}

To the China-Latin American United Laboratory for Rail Transportation and to FAPERJ and CNPq for the financial support.

\section{References}

1. Wu MK, Ashburn JR., Torng CJ, Hor PH, et al. Superconductivity at 93K in a New MixedPhase Y-Ba-Cu-O Compound System at Ambient Pressure. Physical Review Letters, 1987;58(9):908-910. doi: 10.1103/physrevlett.58.908

2. Murakami M., Oyama T, Fujimoto H, Taguchi T, et al. Large Levitation Force due to Flux Pinning in $\mathrm{YBaCuO}$ Superconductors Fabricated by Melt-Powder-Melt-Grouth Process. Japanese Journal of Applied Physic, 1990;29(11):1191-1194. doi: 10.1143/jjap.29.11991

3. Wang S, Wang J, Wang X, Ren Z, et al. The Man-Loading High-Temperature Superconducting MagLev Test Vehicle. IEEE Transactions on Applied Superconductivity, 2003;13(2):2134-2137. doi: 10.1109/tasc.2003.813017

4. Deng Z, Zhang W, Zheng J, Wang B, et al. A High-Temperature Superconducting MaglevEvacuated Tube Transport (HTS Maglev-ETT) Test System. IEEE Transactions on Applied Superconductivity, 2017;27(6). ASN:3602008. doi: 10.1109/tasc.2017.2716842 
5. Deng Z, Zhang W, Zheng J, Ren Y, et al. A high temperature superconducting Maglev ring test line developed in Chengdu, China. IEEE Transactions on Applied Superconductivity, 2016;26(6). ASN:3602408. doi: 10.1109/tasc.2016.2555921

6. Schultz L, de Haas O, Verges P, Beyer C, et al. Superconductively Levitated Transport System - the SupraTrans project, IEEE Transactions on Applied Superconductivity, 2005;15(2):2301-2305. doi: 10.1109/tasc.2005.849636

7. Stephan RM, de Andrade Jr. R, Santos G, Neves MA, et al. Levitation Force and Stability of Superconducting Linear Bearings Using NdFeB and Ferrite Magnets, Physica C, Superconductivity, 2003;386:490-494. doi: 10.1016/s0921-4534(02)02235-9

8. Stephan RM, Nicolsky R, Neves MA, Ferreira AC, et al. A Superconducting Levitation Vehicle Prototype. Physica C, Superconductivity, 2004;408:932-934. doi: 10.1016/j. physc.2004.03.169

9. Stephan RM, de Andrade Jr. R., Ferreira AC. Superconducting Light Rail Vehicle: A Transportation Solution for Highly Populated Cities. IEEE Vehicular Technology Magazine, 2012;7:122-127. doi: 10.1109/mvt.2012.2218437

10. Stephan RM, de Andrade JrR, Ferreira AC, Sotelo GG. Superconducting Levitation Applied To Urban Transportation. Wiley Encyclopedia of Electrical and Electronics Engineering, 2017. doi: 10.1002/047134608X.W8346.

11. Technology Readiness Assessment. USA Department of Defense, 2011.

12. Technology Readiness Assessment Guide. USA Department of Energy, 2011.

\section{Information about the authors:}

Stephan Richard, Dr.-Ing.;

ORCID: 0000-0002-8019-1016

E-mail: rms@ufrj.br

Costa Felipe, $\mathrm{PhD}$ student;

ORCID: 0000-0002-9457-2805

E-mail: felipe@pee.ufrj.br

Rodriguez Elkin, D.Sc.;

ORCID: 0000-0001-8570-9139

E-mail: elkin@dee.ufrj.br

Deng Zigang, Dr. Prof.;

ORCID: 0000-0001-7937-9081

E-mail: deng@swjtu.cn

\section{To cite this article:}

Stephan R, Costa F, Rodriguez E, Deng Z. Retrospective and Perspectives of the Superconducting Magnetic Levitation (SML) Technology Applied to Urban Transportation. Transportation Systems and Technology. 2018;4(3 suppl. 1):195-202. doi: 10.17816/transsyst201843s1195-202 